\title{
Dysregulation of Key Proteinases in Aspergillus fumigatus Induced by Blood Platelets
}

\author{
Bahareh Arghavan $^{1}$, Mohammad Shafiee ${ }^{2,3}$, Seyed Jamal Hashemi ${ }^{1}$, \\ Sadegh Khodavaisy ${ }^{1}$, Nazanin Hosseinkhan ${ }^{4}$, Mojtaba Didehdar, \\ Muhammad Getso ${ }^{1,6}$, Aliasghar Ayatollahi ${ }^{7}$, Sassan Rezaie*1
}

\begin{abstract}
Background: Aspergillus fumigatus is the most common species causing invasive aspergillosis (IA), a lifethreatening infection with more than $80 \%$ mortality. Interactions between $A$. fumigatus and human blood platelets lead to intravascular thrombosis and localized infarcts. To better understand $A$. fumigatus pathogenesis, we aimed to analyze the genetic basis of interactions between the pathogen and blood platelets.

Methods: A bioinformatic pipeline on microarray gene expression dataset, including analysis of differentially expressed genes (DEGs) using Limma R package and their molecular function, as well as biological pathways identification, was conducted to find the effective genes involved in IA. In the wet phase, the gene expression patterns following fungal exposure to blood platelets at 15, 30, 60, and $180 \mathrm{~min}$ were evaluated by quantitative reverse transcriptase-PCR analysis.

Results: Three genes encoding aspartic endopeptidases including (Pep1), (Asp f 13), and ( $\beta$-glucanase) were the standing candidates. The invasion-promoting fungal proteinase-encoding genes were downregulated after $30 \mathrm{~min}$ of hyphal incubation with blood platelets, and then up-regulated at 60 and 180 min, although only Pep1 was greater than the control at the 60 and 180 min time points. Also, the same genes were downregulated in more the clinical isolates relative to the standard strain CBS 144.89 .

Conclusions: Our findings delineate the possible induction of fungal-encoded proteinases by blood platelets. This provides a new research line into A. fumigatus' molecular pathogenesis. Such insight into IA pathogenesis might also guide researchers toward novel platelet-based therapies that involve molecular interventions, especially in IA patients.
\end{abstract}

Keywords: Aspergillus fumigatus, Blood Platelets, Gene Expression, Microarray Analysis, Proteinases.

\section{Introduction}

Aspergillus fumigatus is the most common of the Aspergillus species that cause invasive fungal infection in immunocompromised individuals including organ transplant recipients, leukemia, AIDS, and covid-19 patients, and those receiving immunosuppressive therapy for autoimmune or neoplastic diseases $(1,2)$. Invasive aspergillosis (IA) is a life-threatening infection with a mortality rate of about $85 \%$ in untreated patients; adequate intervention increases patient survival (3-5). Thus, molecular biologists are trying to develop better diagnostic laboratory tests for IA patients than those currently

1: Department of Medical Parasitology and Mycology, School of Public Health, Tehran University of Medical Sciences, Tehran, Iran.

2: Department of Medical Laboratory Sciences, Khomein University of Medical Sciences, Khomein, Iran.

3: Stem Cell Research Center, Golestan University of Medical Sciences, Gorgan, Iran.

4: Endocrine Research Center, Institute of Endocrinology and Metabolism, Iran University of Medical Sciences, Tehran, Iran.

5: Department of Parasitology and Mycology, School of Medicine, Arak University of Medical Sciences, Arak, Iran.

6: Department of Medical Microbiology and Parasitology, College of Health Sciences, Bayero University, Kano, Nigeria.

7: Laboratory Sciences Research Center, Golestan University of Medical Sciences, Gorgan, Iran.

*Corresponding author: Sassan Rezaie; Tel: +98 21 88951392; E-mail: srezaie@tums.ac.ir.

Received: 25 Nov, 2020; Accepted: 13 Dec, 2020 
available (6). In susceptible individuals, the most frequent manifestation is invasive pulmonary aspergillosis, in which inhaled conidia lodge in the lung and germinate into mycelia within the alveoli. One important process in IA is angioinvasion by fungal hyphae, which results in endothelial damage, local erosion, and deep tissue invasion. Consequently, interactions between Aspergillus and blood platelets lead to intravascular thrombosis and localized infarcts (7-9). The interplay between platelets and Aspergillus has been shown to be a multifactorial process (10). Human platelets exhibit specific features of classic cell-mediated immunity and play important roles in antifungal host defense in IA by preventing germination, hyphal elongation, viability $(11,12)$, and increased susceptibility to antifungal drugs in vitro (13-16). During exposure to Aspergillus, platelets interact directly with hyphae, aggregate, surround the fungus, and release stored serotonin from their dense granules within $30 \mathrm{~min}$ (13). Aspergillusinduced activation of platelets also causes tissue damage and thrombosis, a well-known histopathological hallmark in IA patients. Thrombosis results from the exaggerated release of inflammatory mediators (inflammatory necrosis) by the procoagulantcomplement proteins, which promote vascular endothelial damage and subsequent release of tissue factor from the vessels following invasion by the fungal hyphae $(8,11,17-19)$. However, some studies have shown that blood platelets contribute to hemostasis and inflammation during thrombosis. Moreover, they play an important role in antimicrobial host defenses (20). For example, they affect Staphylococcus aureus (21) and Candida albicans (22) viability. Also, platelets can internalize bacteria and viruses (20) through contact-dependent mechanisms or platelet microbial peptides (PMPs) (23). Recent data has demonstrated that resistance of $C$. albicans to PMPs increases the severity of experimental Candida endocarditis (24). It was observed that serotonin, stored in platelet granules, has fungicidal activity against Aspergillus species and reduces fungal virulence (25). On that basis, we attempted to determine the interaction between platelets and Aspergillus species in more detail. Information on the antifungal role of platelets against Aspergillus spp. is limited. One study showed that activated human platelets express the CD63 glycoprotein after interacting with $A$. fumigatus. Furthermore, platelets help polymorphonuclear leukocytes (PMNs) to attack aspergilli. Perkhofer et al., reported that platelet granules contain serotonin, which is immediately released after contact with Aspergillus spp. Thus, on Aspergillus exposure, platelets considerably affect germination and hyphal elongation $(13,14,26)$.

Although previous reports have shown that study of aberrant gene expression and genetic locus association can be helpful in understanding diagnosis and/or treatment of infectious and noninfectious diseases, few reports address IA caused by A. fumigatus (27-30).

Several studies examined the transcriptional response of Aspergillus spp. exposed to human cells and reported various A. fumigatus genes expressed in response to neutrophils (31), monocyte-derived dendritic cells (32), and airway epithelial cells (33). Genome-wide microarray analysis identified the differential expression of almost 9500 genes in A. fumigatus following exposure to human platelets (34).

Better understanding of the interactions between platelets and A. fumigatus invasion factors might provide important insight into the pathogenesis of IA for patient treatment and the future design of novel diagnostic or prognostic kits. Using a bioinformatic analysis pipeline on microarray data to identify effective genes, and then using Q-RT-PCR analyses, the present study aimed to evaluate differential expression of A. fumigatus genes following exposure to human blood platelets after 15, 30, 60, and $180 \mathrm{~min}$ of contact.

\section{Materials and Methods \\ Analysis pipeline on the gene expression microarray dataset}

A microarray gene expression dataset of $A$. fumigates induced by human platelets in vitro (E-MTAB-3024) was retrieved from the Array Express database 
(https://www.ebi.ac.uk/arrayexpress/experime nts/E-MTAB-3024). This dataset consists of triplicates for each of five groups including untreated fungi as the control, and after 15, 30, 60 , and $180 \mathrm{~min}$ of exposure to human platelets.

\section{Analysis of DEGs using Limma R package} Limma package was used in R.3.5.0 to identify the differentially-expressed genes (DEGs) between the following pairs: AF-15 min vs. AF-control, AF-30 min vs. AF-control, AF-60 min vs. AF-control, AF-180 min vs. AFcontrol, AF-30 min vs. $15 \mathrm{~min}, \mathrm{AF}-60 \mathrm{~min}$ vs. AF-30 min and AF-180 min hours vs. AF-60 min. Applying $\leq 0.01$ filter for the $P$ value and $\geq$ $|1|$ for $\operatorname{logFC}$, the up and down-regulated genes were identified in each group.

\section{Annotation, Visualization. and Integrated Discovery analysis of DEGs}

The DEGs in the different pairs were then introduced to The Database for Annotation, Visualization, and Integrated Discovery (DAVID) v6.8 (https://david.ncifcrf.gov/) to identify their molecular functions and biological pathways.

\section{Aspergillus fumigatus culture}

An A. fumigatus strain isolated from an IA patient was provided for the platelet-fungus exposure experimental. The isolate was grown on Sabouraud Dextrose Agar (SDA, Merck Co., Darmstadt, Germany) and incubated at $35{ }^{\circ} \mathrm{C}$ for four days. The conidial suspension was harvested by flooding each colony with $2 \mathrm{~mL}$ of RPMI1640. The harvested conidia were counted on a hemocytometer and resuspended at $1 \times 10^{5}$ $-2.5 \times 10^{5}$ colony forming units (CFUs)/mL. The size and viability of the inoculum were determined using quantitative colony counts. Hyphae were produced from germination of conidia incubated in RPMI1640 at $37{ }^{\circ} \mathrm{C}$ for $16 \mathrm{~h}$ with shaking at 150 rpm. Under these conditions, almost $90 \%$ of the conidia formed hyphae (13).

\section{Preparation and Storage of Platelet Concentrates (PCs)}

Fresh PCs were sourced from the Central Blood Transfusion Organization of Tehran Province, Tehran. Platelets were collected from healthy donors and prepared by Random Donor Platelets. All the donors gave written informed consent to use the remaining PCs for research purposes. All residual PCs collected were de-identified and used anonymously. Platelets were stored at $22-24{ }^{\circ} \mathrm{C}$ for a maximum of two days, and platelet aggregation analyses were used for quality control. Platelets were used at $6 \times 10^{8}$ cells $/ \mathrm{mL}$.

\section{Co-culture of platelets with fungal hyphae}

Before exposure to platelets, the fungal hyphae were cultivated via conidial germination by incubation of conidial suspension in RPMI1640 at $37{ }^{\circ} \mathrm{C}$ for $16 \mathrm{~h}$. The platelet-fungus infection assays were performed in wells of six-well plates. The platelets were added to the hyphae at a ratio of 100:1, and plates were incubated for 15,30,60, and $180 \mathrm{~min}$. Untreated hyphae served as control. All samples were assessed in triplicate. To confirm platelet-fungus infection, hyphae were incubated with platelets and examined at the 30 min timepoint $(13,35)$.

\section{Clinical samples and standard strain CBS 144.89 as control}

To practically confirm the platelets-fungus exposure, A. fumigatus clinical isolates from five IA patients were obtained from the reference culture collection of the Tehran Medical Mycology Laboratory (TMML). Strain CBS 144.89, isolated from an IA patient in France and obtained from the CBS-KNAW Fungal Biodiversity Centre or Centraalbureau voor Schimmelcultures (Central Bureau of Fungal Cultures), Utrecht, the Netherlands, was considered as standard. Of the five TMML strains, four were A. fumigatus isolated from bronchoalveolar lavage (BAL) samples and one from a pseudo mycetoma lesion with 
severe necrosis. All six isolates were grown on SDA (Merck Co., Darmstadt, Germany) at 35 ${ }^{\circ} \mathrm{C}$ for four days. The conidial suspension was harvested by flooding each colony with $2 \mathrm{~mL}$ of RPMI-1690. The conidia were counted on a hemocytometer and adjusted to a concentration of $1 \times 10^{5}$ colony-forming units $/ \mathrm{mL}$ (CFUs/mL). For hyphal growth, conidia were incubated at $37{ }^{\circ} \mathrm{C}$ for $16 \mathrm{~h}$ with shaking.

\section{RNA isolation}

Total RNAs were extracted from all $A$. fumigatus strains by RNX-Plus solution (SinaClon) according to the manufacturer's instructions with chloroform, isopropanol, and $75 \%$ ethanol. RNA was treated with DNase I (CinnaGen Co, Iran) to remove any potential DNA contamination. For quality control, the RNA purity was measured at A260/A280 in a spectrophotometer. The ratios were generally greater than 1.6.

\section{cDNA synthesis}

First-strand cDNA was synthesized using an Easy $^{\mathrm{TM}}$ cDNA Synthesis Kit (Parstous biotechnology, Iran) according to the manufacturer's instructions. For each sample, a no-RT control was used in parallel with the DNase-treated RNA to detect any potential non-specific genomic DNA amplification.

\section{Quantitative reverse transcriptase polymerase chain reaction ( $Q-R T-P C R)$}

Q-RT-PCR was performed with the Step One Plus Real-Time PCR System (Applied
Biosystems, Foster City, USA) using a RealQ Plus 2x Master Mix Green kit (Pishgam, Iran). Pep1/aspergillopepsin F (Pep1), allergenic cerato-platanin (Asp f 13), and endo-1,3 betaglucanase ( $\beta$-glucanase) gene expression was evaluated in the A. fumigatus hyphae after exposure to platelets for the various incubation times. The same procedure was also performed on the five clinical isolates from TMML and a standard strain, CBS 144.89. All experiments were performed at least in duplicate using a thermal cycler under the following conditions: $95{ }^{\circ} \mathrm{C}$ for 15 seconds, $65{ }^{\circ} \mathrm{C}$ for 15 seconds, and $60{ }^{\circ} \mathrm{C}$ for $1 \mathrm{~min}$. Melting curves were then determined with temperatures ranging from 65 to $95{ }^{\circ} \mathrm{C}$. Specific primers for the genes were designed using AlleleID 6.0 (Premier Biosoft, Palo Alto, CA, USA) and Gene Runner software (Hastings Software, Inc., Hastings, NY, USA). Primer sequences for amplifying cDNA of Asp f 13, Pep1, $\beta$-glucanase, and $\beta$ actin (as an internal control) genes are listed in Table 1. The product lengths were 171, 158, 191, and $206 \mathrm{bp}$, respectively, and the annealing temperature was $58{ }^{\circ} \mathrm{C}$. To compensate for variations in the amount of input RNA and the efficacy of reverse transcriptase, $\beta$-actin mRNA was quantified as an internal control and all gene expression was normalized to it. Non-template controls for each primer set were assayed for potential of DNA contamination or primer dimerization. To calculate the relative fold change of each gene, we used the $2^{-\Delta \mathrm{Ct}}$ method.

Table 1. Sequence of forward $(\mathrm{F})$ and reverse (R) primers used in this study for amplification of three genes encoding invasionpromoting fungal proteinases listed in the left column.

\begin{tabular}{|c|c|}
\hline Genes & Sequence of primers \\
\hline Pepl ${ }^{a}$ & $\begin{array}{l}F: \text { 5'CCG TCA ATC TTC CAG CTG TCT3', } \\
R: 5^{\prime} A G T C C A \text { AGT TCA GGG TCG TTC3, }\end{array}$ \\
\hline$A s p f 13^{b}$ & $\begin{array}{l}F: 5 \text { 'TCA CCA CAC CCA TCT CTC TCA3', } \\
R: 5^{\prime} G A G C A G \text { GAA ACG TCG TTC ATC3, }\end{array}$ \\
\hline$\beta$-glucanase ${ }^{c}$ & $\begin{array}{l}F: 5^{\prime} C T C \text { ATC AGC AAC GCT CCC TAA3', } \\
R: 5^{\prime} T G C \text { TCT CAA TAC GGC CTG AAG3, }\end{array}$ \\
\hline$A C T^{d}$ & $\begin{array}{l}F: 5^{\prime} G T C A C T \text { GTG CAG ATT GTC GC3', } \\
R: \text { ' 'TCA GGA TGA GGA AAG GGG GA3' }\end{array}$ \\
\hline
\end{tabular}

${ }^{a}$ Pep 1: Aspartic endopeptidase Pep1/aspergillopepsin F.

${ }^{b}$ Asp f 13: allergenic cerato-platanin.

${ }^{c} \beta$-glucanase: endo-1,3 beta-glucanase.

${ }^{d} A C T: \beta$-actin 


\section{Statistical analysis}

Data are presented as mean values and error bars indicated as \pm S.E.M. The significance of differential expression was analyzed using the repeated-measures ANOVA. Q-RT-PCR data was adjusted based on the exact PCR efficiency. SPSS version 18 was used for all analyses. $\mathrm{P}<0.05$ was considered statistically significant.

\section{Results}

\section{Candidate genes encoding aspartic endopeptidases and endo-1,3 beta-glucanase enzymes}

The deregulated genes in all pairwise comparisons are shown in supplementary Table 1. Functional annotation of deregulated genes in different groups of pairwise comparisons

A)

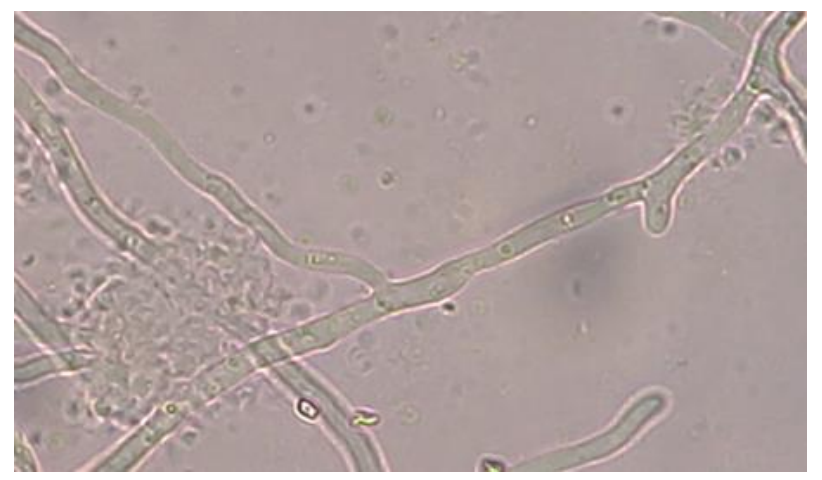

C)

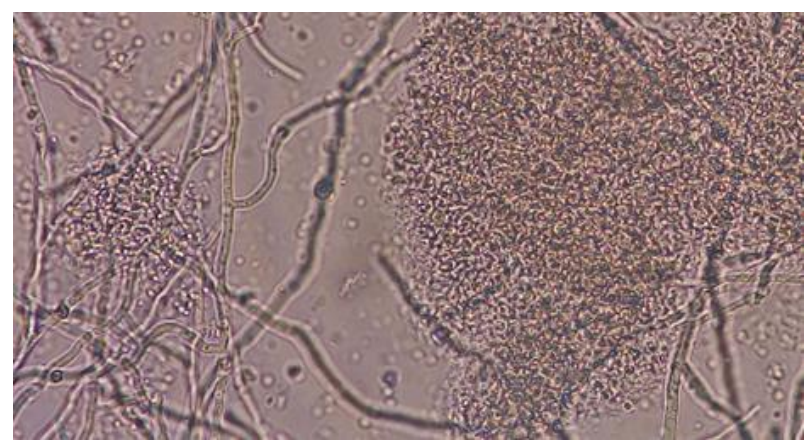

guided us to select the candidate genes Pep1, Asp f 13, and $\beta$-glucanase, which were detected as deregulated. Their involvement in $A$. fumigates has been previously reported.

\section{Platelet aggregation around the hyphae}

Platelets were exposed to hyphae for the various incubation times. Untreated hyphae served as control. The platelet-fungus contact was evaluated using an inverted light microscope. Platelet aggregation was seen as early as $15 \mathrm{~min}$ and increased over time. After $180 \mathrm{~min}, 95 \%$ of the hyphae were surrounded by platelet aggregates (Figs. 1A-1D). The hyphae-platelet interactions can be clearly seen with higher magnification (Fig. 2).
B)

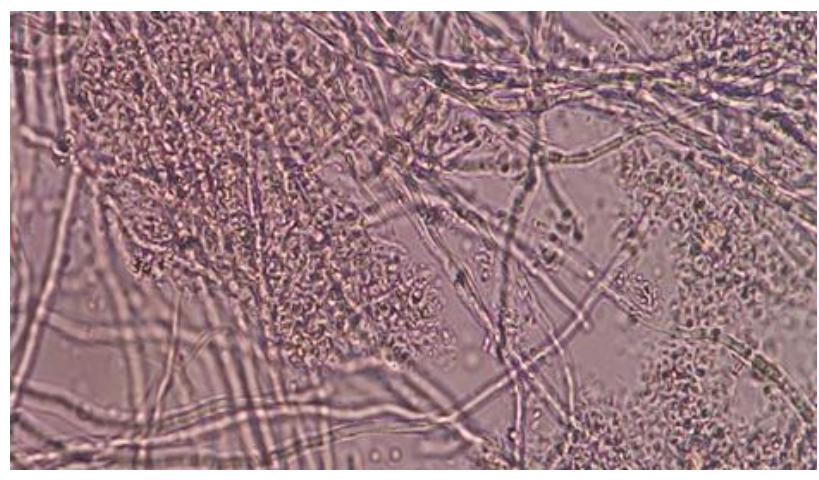

D)

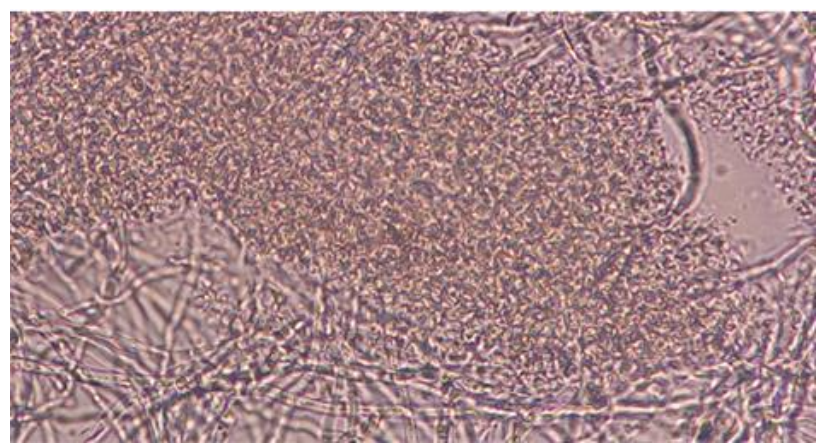

Fig. 1. A. fumigatus hyphae surrounded by platelet aggregates over time (A, $15 \mathrm{~min}, \mathrm{~B} ; 30 \mathrm{~min}, \mathrm{C} ; 60 \mathrm{~min}, \mathrm{D} ; 180 \mathrm{~min})$ identified by light microscopy (400x magnification). Fungal hyphae were cultivated via conidial germination by incubation of conidial suspension in RPMI-1640 at $37{ }^{\circ} \mathrm{C}$ for $16 \mathrm{~h}$. The platelet-fungus infection assays were performed in wells of six-well plates. The platelets were added to the hyphae at a ratio of 100:1, and platelets were incubated for $15,30,60$, and $180 \mathrm{~min}$. Untreated hyphae served as control. 


\section{Arghavan B et al}
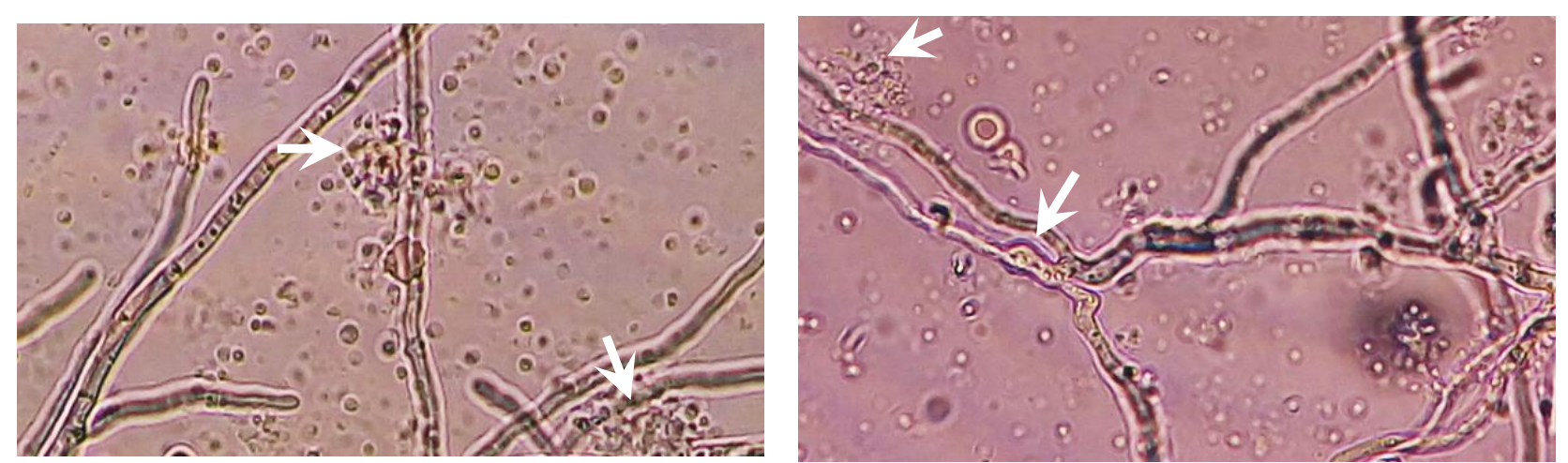

Fig. 2. Inverted light micrographs (400x magnification) showed hyphal-platelet interactions after $30 \mathrm{~min}$ (A) and 60 $\min (\mathrm{B})$. The assays were performed as in Figure 1.

\section{Aberrant expression of DEGs}

The relative expression of Asp f 13, Pep1, and $\beta$-glucanase in the hyphae was measured by QRT-PCR after exposure to platelets and compared with that of control hyphae. All three candidate genes were significantly downregulated after $30 \mathrm{~min}$ of platelet-mycelia exposure (Fig. 3). Asp f 13-encoding gene expression was significantly less than control at 30 and $180 \mathrm{~min}$; at no time point was expression significantly greater than the control; however, Asp f 13 gene expression was significantly greater at 60 than at $30 \mathrm{~min}$. Pep1encoding gene expression was significantly less than control at $30 \mathrm{~min}$, but significantly greater at $60 \mathrm{~min}$. Pep1 gene expression is also significantly greater at 60 and 180 than at 30 min. $\beta$-glucanase encoding gene expression was significantly less than control at 30 and $60 \mathrm{~min}$, and was significantly greater at 60 and $180 \mathrm{~min}$ than at $30 \mathrm{~min}$. We also evaluated the expression changes of Asp f 13, Pep1, and $\beta$ glucanase in the fungal cultures of the five TMML clinical isolates and standard strain CBS 144.89. Expression of these genes in four of the clinical isolates was not significantly different from the standard strain; however, expression of one bronchoalveolar lavage isolate, BAL4, was significantly greater than the standard for all three genes. (Fig. 4).

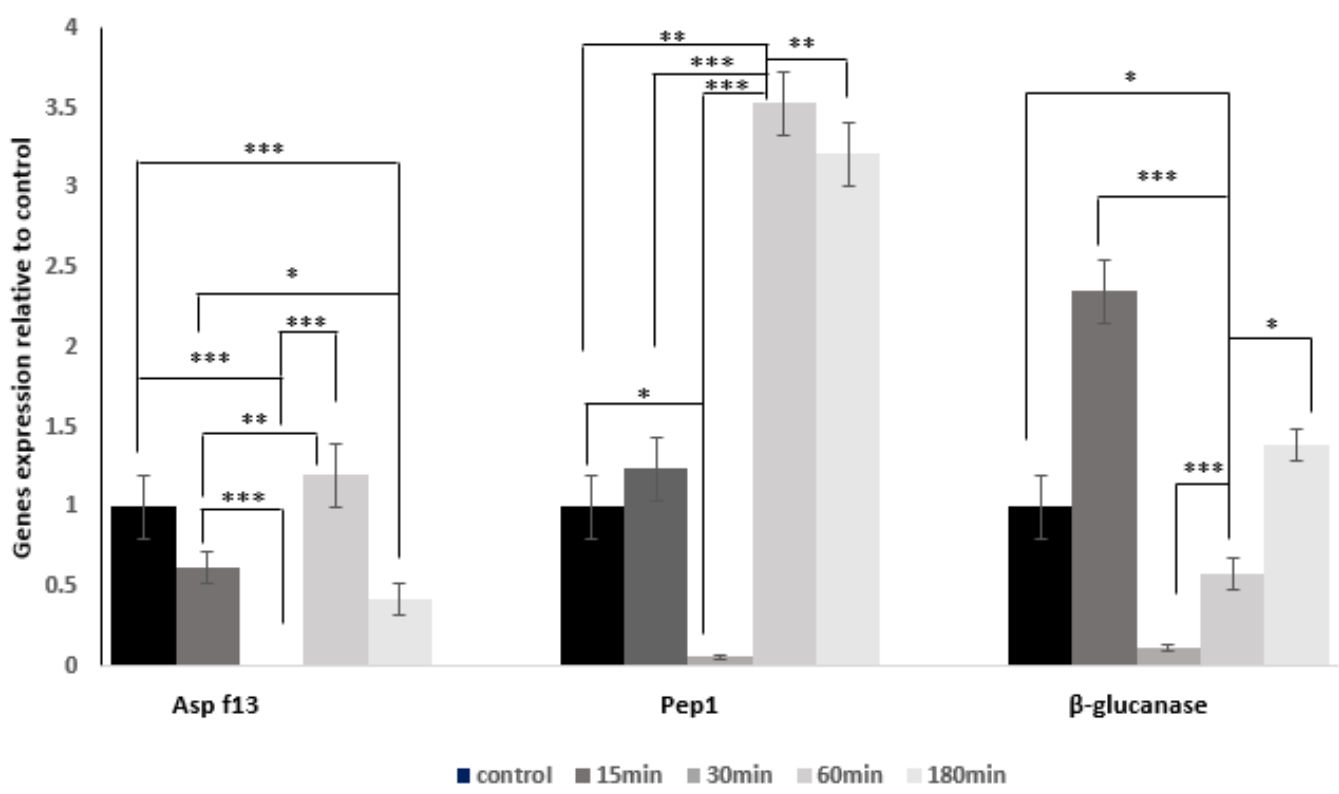

Fig. 3. Relative expression of the genes encoding the aspartic endopeptidases allergenic cerato-platanin (Asp $\mathrm{f}$ 13), aspergillopepsin F (Pep1), and endo-1,3 beta-glucanase ( $\beta$-glucanase) in A. fumigatus hyphae infecting human blood platelets for 15,30,60, and 180 min. Controls were A. fumigatus hyphae with no platelets. All three genes were downregulated from control to $30 \mathrm{~min}$. Then they were up-regulated from $30 \mathrm{~min}$ to 60 and $180 \mathrm{~min}$; however, Asp f 13 and Pep1 down-regulated from 60 to 180 min, while endo-1,3 beta-glucanase expression was increased from 60 to $180 \mathrm{~min}$. 


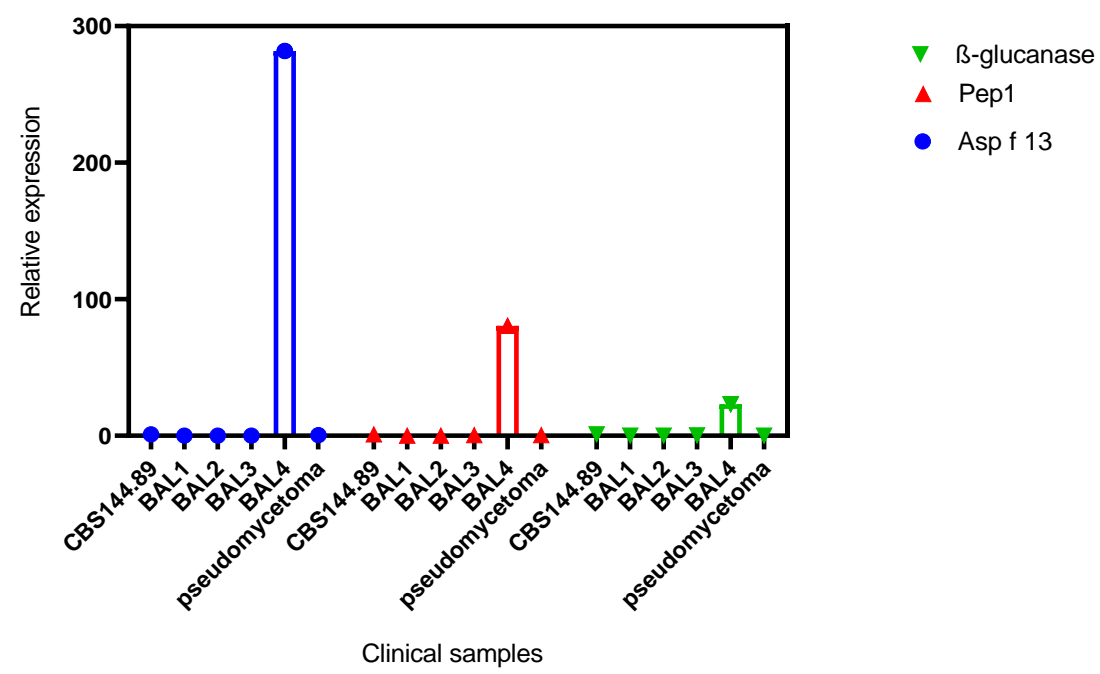

Fig. 4. Relative expression of Asp f 13, Pep1, and endo- $\beta$-1,3-glucanase genes in the five clinical isolates and standard strain CBS 144.89. All three genes in four of the five clinical isolates were expressed at the same low level as the standard strain CBS 144.89, but in one isolate, BAL4, all three genes were up-regulated relative to the standard strain.

\section{Discussion}

Few studies on the transcriptional response of Aspergillus spp. to human cells have been reported. The available studies identified DEGs in A. fumigatus conidia exposed to neutrophils (31), monocyte-derived immature dendritic cells (32), and 16HBE140 human bronchial epithelial cells (33). Based on our bioinformatics analyses, we chose three candidate genes that encode essential enzymes as thrombotic and angioinvasive components in IA: Aspartic endopeptidase Pep1/aspergillopepsin F, allergenic ceratoplatanin Asp f 13, and endo-1,3 beta-glucanase (AFUA_5G13300, AFUA_2G12630, AFUA_6G14540). Perkhofer etal., studied the transcriptional response of $A$. fumigatus hyphae to human platelets in a time course and reported genes that were commonly identified in previous studies. Those genes were deregulated after exposure to platelets, and were associated with regulation of biological processes, molecular functions, pathogenesis, and cellular composition (34). In the present study, using experimental Q-RT-PCR, we validated the microarray dataset of the Perkhofer study to evaluate the expression changes of Pep1, Asp $\mathrm{f}$ 13 , and $\beta$-glucanase genes in A. fumigatus cocultured with human platelets, and also in the fungal cultures of five clinical isolates with a standard strain CBS 144.89. In this study, we aimed to gain a better understanding towards elucidation of probable interactions between platelets and fungal crills as they are involved in the thrombotic process. Because the fungal cell wall is an important defense against host immune machinery in IA, it might be a likely target of the host immune system and antifungal drugs $(36,37)$. Exposure of $A$. fumigatus to platelets significantly effects germination and hyphal elongation (13). Moreover, its interaction with platelets leads to the downregulation of some genes related to cell wall integrity, including cell wall galactomannoprotein (Afu4g00870), cell wall glucanase Utr2 (Afu2g03120), cell wall protein (Afu3g08110), and alpha-1,3-glucan synthase Ags2 (Afu2g11270). Galactomannoprotein and Utr2 were induced in the fungal infection (38). Utr2 and Afu $3 g 08110$ expression was increased in $A$. fumigatus exposed to human airway epithelial cells and human immature dendritic cells (32, 33). In A. fumigatus, $\beta-1,3$-glucan is an important constituent that confers rigidity to the cell wall. The $\beta$-1,3-glucan hydrolyzing enzymes are divided into exo- and endo- $\beta$ - $1,3-$ glucanases (39). The endo- $\beta$-1,3-glucanase cleaves inside a glucan chain somewhat randomly. $\beta-1,3$-glucanases, especially endo$\beta-1,3$-glucanases, play a principal role in cell 
wall softening during germination and mycelial elongation (40). Endo- $\beta$-1,3glucanases (AFUA_6G14540) gene expression might be expected change to maintain hyphal elongation during contact with platelets. In addition to cell wall enzymes, some important A. fumigatus extracellular enzymes produced in IA that can trigger thrombosis are aspartic proteases, which are named aspergillopepsin and alkaline serine proteases. Secreted aspergillopepsin (Pep1), which matches the known Asp F10 allergen as an aspartic protease, and Asp f 13/Alp2, an alkaline serine protease, have elastinolytic activities on blood vessel walls that can lyse human elastin, collagens, and fibronectin (4). This might be attributable to an initial rapid response to the hyphae-platelet contact, followed by a delayed response of secretory components released from platelet granules. The changes in gene expression between 15 and $180 \mathrm{~min}$, may be due to the adaptation process of hyphaeplatelet contact. However, we observed upregulation of $\beta$-glucanase gene from 60 to 180 min, which might be due to continuing fungal growth. Also, Asp 1, 3 and Pep1 were down regulated over that time. According to a previous study, during fungal growth, soluble A. fumigatus proteases could induce platelet aggregation and granule release. It has been indicated that A. fumigatus is an effective inducer of platelets, which may be co-activated by thrombin stimulation (41). As described in the results, dysregulation of the candidate genes varied between the five TMML clinical isolates, with only one of them being up regulated (Fig. 4). This result may be due to patient differences including immune system suppression, neutropenic condition, antifungal therapy, and others. Histological features of tissue damage in invasive pulmonary aspergillosis differ between neutropenic and

\section{References}

1. Armstrong-James D, Youngs J, Bicanic T, Abdolrasouli A, Denning DW, Johnson E, et al. Confronting and mitigating the risk of COVID19 associated pulmonary aspergillosis. Eur Respir J. 2020;56(4):2002554. non-neutropenic patients; for example, inflammatory necrosis is significant in nonneutropenics, while angioinvasion is dominant in neutropenics (42). Also, studies have shown that platelets play a critical role in the pathogenesis of aspergillosis; thus, the infection might differ between patient groups according to the presence or absence of thrombocytopenia (43). Understanding the interactions between platelets and $A$. fumigatus invasion factors will provide insight into IA pathogenesis. Essential characteristics, such as immune cell activation, complement system recruitment, and mycocide component release have previously been elucidated and currently capture the attention of researchers; their results will direct future studies. A principal attribute in the bifunctional role of plateletassociated responses is that the useful antifungal effects and consequential disease burden reduction are offset by destructive outcomes including excessive inflammation and thrombosis. Moreover, the role of platelets in IA, if properly explored, may translate into new platelet-based therapies. We believe further studies are warranted to elucidate the overall significance of platelets in Aspergillus infection.

\section{Acknowledgements}

We thank the Iranian Blood Transfusion Organization (IBTO) for providing fresh human blood platelets; Office of the Vice Dean for Research Affairs in Tehran University of Medical Sciences (TUMS) for assigning a research grant to this project, and the Ethics Committee TUMS for approving the project (IR.TUMS.SPH.REC.1397.108).

The authors declare that they have no conflict of interest.

2. Rutsaert L, Steinfort N, Van Hunsel T, Bomans P, Naesens R, Mertes H, et al. COVID19-associated invasive pulmonary aspergillosis. Annals of Intensive Care. 2020;10(1):1-4. 
3. Brown GD, Denning DW, Gow NA, Levitz SM, Netea MG, White TC. Hidden killers: human fungal infections. Science Translational Medicine. 2012;4(165):165rv13.

4. Abad A, Fernández-Molina JV, Bikandi J, Ramírez A, Margareto J, Sendino J, et al. What makes Aspergillus fumigatus a successful pathogen? Genes and molecules involved in invasive aspergillosis. Revista iberoamericana de micologia. 2010;27(4):155-82.

5. Obar JJ. Sensing the threat posed by Aspergillus infection. Current Opinion in Microbiology. 2020;58:47-55.

6. Fontaine T, Latgé J-P. Galactomannan Produced by Aspergillus fumigatus: An Update on the Structure, Biosynthesis and Biological Functions of an Emblematic Fungal Biomarker. Journal of Fungi. 2020;6(4):283.

7. Ben-Ami R, Lewis RE, Kontoyiannis DP. Enemy of the (immunosuppressed) state: an update on the pathogenesis of Aspergillus fumigatus infection. British journal of haematology. 2010;150(4):406-17.

8. Filler SG, Sheppard DC. Fungal invasion of normally non-phagocytic host cells. PLoS pathogens. 2006;2(12).

9. Latge J-P, Chamilos G. Aspergillus fumigatus and aspergillosis in 2019. Clinical microbiology reviews. 2019;33(1).

10. Deshmukh H, Rambach G, Sheppard DC, Lee M, Hagleitner M, Hermann M, et al. Galactosaminogalactan secreted from Aspergillus fumigatus and Aspergillus flavus induces platelet activation. Microbes and Infection. 2020.

11. Klinger MH, Jelkmann W. Role of blood platelets in infection and inflammation. Journal of interferon \& cytokine research. 2002;22(9):913-22.

12. Page C. Platelets as inflammatory cells. Immunopharmacology. 1989;17(1):51-9.

13. Perkhofer S, Kehrel BE, Dierich MP, Donnelly JP, Nussbaumer W, Hofmann J, et al. Human platelets attenuate Aspergillus species via granule-dependent mechanisms. Journal of Infectious Diseases. 2008;198(8):1243-6.

14. Perkhofer S, Striessnig B, Sartori B, Hausott B, Ott HW, Lass-Flörl C. Interaction of platelets and anidulafungin against Aspergillus fumigatus.
Antimicrobial agents and chemotherapy. 2013;57(1):626-8.

15. Perkhofer S, Trappl K, Nussbaumer W, Dierich MP, Lass-Flörl C. Potential synergistic activity of antimycotic substances in combination with human platelets against Aspergillus fumigatus. Journal of Antimicrobial Chemotherapy. 2010;65(6):1309-11.

16. Tischler BY, Tosini NL, Cramer RA, Hohl TM. Platelets are critical for survival and tissue integrity during murine pulmonary Aspergillus fumigatus infection. PLoS pathogens. 2020;16(5):e1008544.

17. Speth C, Rambach G, Lass-Florl C. Platelet immunology in fungal infections. Thrombosis and haemostasis. 2014;112(4):632-9.

18. Verschoor A, Langer HF. Crosstalk between platelets and the complement system in immune protection and disease. Thrombosis and haemostasis. 2013;110(5):910-9.

19. Dagenais TR, Keller NP. Pathogenesis of Aspergillus fumigatus in invasive aspergillosis. Clinical microbiology reviews. 2009;22(3):44765.

20. Fitzgerald JR, Foster TJ, Cox D. The interaction of bacterial pathogens with platelets. Nature Reviews Microbiology. 2006;4(6):44557.

21. Yeaman MR, Puentes S, Norman D, Bayer A. Partial characterization and staphylocidal activity of thrombin-induced platelet microbicidal protein. Infection and immunity. 1992;60(3):1202-9.

22. Robert R, Mahaza C, Miegeville M, Ponton J, Marot-Leblond A, Senet J-M. Binding of resting platelets to Candida albicans germ tubes. Infection and immunity. 1996;64(9):3752-7.

23. Tang Y-Q, Yeaman MR, Selsted ME. Antimicrobial peptides from human platelets. Infection and immunity. 2002;70(12):6524-33.

24. Casanova M, Lopez-Ribot J, Martinez J, Sentandreu R. Characterization of cell wall proteins from yeast and mycelial cells of Candida albicans by labelling with biotin: comparison with other techniques. Infection and immunity. 1992;60(11):4898-906.

25. Perkhofer $S$, Niederegger $H$, Blum $G$, Burgstaller W, Ledochowski M, Dierich MP, et al. Interaction of 5-hydroxytryptamine 
(serotonin) against Aspergillus spp. in vitro. International journal of antimicrobial agents. 2007;29(4):424-9.

26. Perkhofer S, Trappl K, Nussbaumer W, Dierich MP, Lass-Flörl C. Potential synergistic activity of antimycotic substances in combination with human platelets against. 2010.

27. Sepahi S, Pasdar A, Gerayli S, Rostami S, Gholoobi A, Meshkat Z. CTLA-4 gene haplotypes and the risk of chronic hepatitis $\mathrm{C}$ infection; a case control study. Reports of Biochemistry \& Molecular Biology. 2017;6(1):51.

28. Jamaati H, Bahrami N, Daustany M, Tabarsi $\mathrm{P}$, Farzanegan B, Hashemian SM, et al. Investigating PIK3R3 and ATp2A1 Genes Expressions in Ventilator-Associated Pneumonia Patients Admitted to the Intensive Care Unit of Masih Daneshvari Hospital in 2016. Reports of biochemistry \& molecular biology. 2018;6(2):118.

29. Steenwyk JL, Mead ME, Knowles SL, Raja HA, Roberts CD, Bader O, et al. Variation Among Biosynthetic Gene Clusters, Secondary Metabolite Profiles, and Cards of Virulence Across Aspergillus Species. Genetics. 2020;216(2):481-97.

30. Ries LN, Pardeshi L, Dong Z, Tan K, Steenwyk JL, Colabardini AC, et al. The Aspergillus fumigatus transcription factor RglT is important for gliotoxin biosynthesis and selfprotection, and virulence. PLoS pathogens. 2020;16(7):e1008645.

31. Sugui JA, Kim HS, Zarember KA, Chang YC, Gallin JI, Nierman WC, et al. Genes differentially expressed in conidia and hyphae of Aspergillus fumigatus upon exposure to human neutrophils. PLoS One. 2008;3(7).

32. Morton CO, Varga JJ, Hornbach A, Mezger M, Sennefelder H, Kneitz S, et al. The temporal dynamics of differential gene expression in Aspergillus fumigatus interacting with human immature dendritic cells in vitro. PloS one. 2011;6(1).

33. Oosthuizen JL, Gomez P, Ruan J, Hackett TL, Moore MM, Knight DA, et al. Dual organism transcriptomics of airway epithelial cells interacting with conidia of Aspergillus fumigatus. PLoS One. 2011;6(5).
34. Perkhofer S, Zenzmaier C, Frealle E, Blatzer M, Hackl H, Sartori B, et al. Differential gene expression in Aspergillus fumigatus induced by human platelets in vitro. International Journal of Medical Microbiology. 2015;305(3):327-38.

35. Perkhofer S, Kainzner B, Kehrel BE, Dierich MP, Nussbaumer W, Lass-Flörl C. Potential antifungal effects of human platelets against zygomycetes in vitro. The Journal of infectious diseases. 2009;200(7):1176-9.

36. Zacharias CA, Sheppard DC. The role of Aspergillus fumigatus polysaccharides in hostpathogen interactions. Current opinion in microbiology. 2019;52:20-6.

37. Walsh TJ, Petraitiene R, Petraitis V. Modeling Invasive Aspergillosis: How Close Are Predicted Antifungal Targets? Journal of Fungi. 2020;6(4):198.

38. McDonagh A, Fedorova ND, Crabtree J, Yu Y, Kim S, Chen D, et al. Sub-telomere directed gene expression during initiation of invasive aspergillosis. PLoS pathogens. 2008;4(9).

39. Millet N, Moya-Nilges M, Sachse M, Krijnse Locker J, Latgé JP, Mouyna I. Aspergillus fumigatus exoß (1-3) glucanases family GH55 are essential for conidial cell wall morphogenesis. Cellular microbiology. 2019;21(12):e13102.

40. Mouyna I, Hartl L, Latgé J-P. $\beta$-1, 3-glucan modifying enzymes in Aspergillus fumigatus. Frontiers in microbiology. 2013;4:81.

41. Rodland EK, Ueland T, Pedersen TM, Halvorsen B, Muller F, Aukrust P, et al. Activation of platelets by Aspergillus fumigatus and potential role of platelets in the immunopathogenesis of Aspergillosis. Infect Immun. 2010;78(3):1269-75.

42. Stergiopoulou T, Meletiadis J, Roilides E, Kleiner DE, Schaufele R, Roden M, et al. Hostdependent patterns of tissue injury in invasive pulmonary aspergillosis. American journal of clinical pathology. 2007;127(3):349-55.

43. Rødland EK, Ueland T, Pedersen TM, Halvorsen B, Müller F, Aukrust P, et al. Activation of platelets by Aspergillus fumigatus and potential role of platelets in the immunopathogenesis of Aspergillosis. Infection and immunity. 2010;78(3):1269-75. 